\title{
RUPTURAS DE PARADIGMAS NA ARQUIVOLOGIA CUSTODIAL PARA A PÓS- CUSTODIAL
}

\author{
BREAKDOWN OF PARADIGMS IN CUSTODIAL \\ ARCHIVAL SCIENCE FOR POST-CUSTODIAL
}

\author{
Sandra Sanches da Cunhaa \\ Alexandre Fernalb
}

\begin{abstract}
RESUMO
Objetivo: Desta forma, buscou-se evidenciar e ressaltar os pontos de rupturas paradigmáticos e seus impactos na arquivologia custodial para a pós-custodial. Para tanto, analisou-se as bases da Arquivologia custodial e pós-custodial, demonstrando-se diferenças e similitudes entre elas. Metodologia: Trata-se de uma pesquisa bibliográfica, exploratória, de abordagem qualitativa e documental acerca da literatura científica nacional e internacional publicada livros, artigos, teses e dissertações. Resultados: Ao se apresentar as rupturas de paradigmas as quais deram ensejo as reformulações e reinterpretações conceituais e disciplinares a respeito do tema, embasadas em seus marcos teóricos ao longo da história, quais sejam os seus pontos de ruptura, suas consequências refletidas bem como as novas interpretações, verificouse, assim, a possibilidade de construção de um novo paradigma frente as conjunturas apresentadas no contexto contemporâneo, de se propor novas fórmulas e de uma hodierna interpretação de princípios e métodos, relacionado à análise de organização do conhecimento arquivístico. Conclusão: Ao se demonstrar as rupturas e seus impactos, portanto, observada a complexidade e o dissenso ainda presente acerca da temática, se faz premente a necessidade de contínua reflexão, estudos e contribuições acerca da matéria em questão, no que diz respeito as rupturas paradigmáticas da Arquivologia custodial para pós custodial.
\end{abstract}

Descritores: Arquivologia. Arquivologia Custodial. Arquivologia Pós-Custodial. Paradigmas. Rupturas.

\section{INTRODUÇÃO}

No final do século XX, a partir da década de 1990, o impacto gerado pelo mundo digital começa a traçar, dentro do conceito arquivístico, a necessidade de

\footnotetext{
a Mestranda no Programa de Pós-Graduação em Ciência da Informação pela Universidade Estadual de Londrina (UEL). E-mail: sandrasanchesdacunha@gmail.com.

b Doutorando no Programa de Pós-Graduação em Ciência da Informação pela Universidade Estadual Pauista (UNESP). E-mail: alexandre.fernal@gmail.com.
} 
mudar velhos padrões (VIEIRA, 2013), uma vez que o avanço tecnológico da informação revela um novo desafio cuja produção documental tem como característica, neste momento, as rupturas paradigmáticas contemporâneas, ou seja, um paradigma pós-custodial, com ênfase no acesso à informação contida nos documentos tradicionais e nos documentos gerado por meio eletrônico.

O pensar nas características científicas que implicaram a Arquivologia, sua história e dos arquivos, como se desenvolveu e desenvolve, reflete-se no significado, conceito, teoria e técnica desta ciência que até o final do século XIX, tinha em sua trajetória um paradigma patrimonial, que colocava à Arquivologia como sendo uma auxiliadora da história (SCHMIDT, 2012).

Diante destas conjunturas, o objetivo central dessa pesquisa foi analisar os impactos e consequências que as rupturas paradigmáticas causaram na Arquivologia Custodial para o Pós-Custodial no percurso percorrido pela Arquivologia, considerando-se se o processo desencadeado no final dos anos 80, qual seja o avanço tecnológico, foi um fator decisivo para que houvesse uma ruptura de paradigma, ocasionando uma mudança no objeto científico, bem como se existe um consenso a respeito dessa ruptura na Arquivologia.

Nesse contexto, tem-se um sujeito informacional com perfil diferente do habitual, cujo comportamento se repete de forma prática e tradicional e que começa a ser repensado, no que se refere à sua vertente, isto é, uma quebra de paradigmas.

Ademais, ao se pautar nas bases da Arquivologia, demonstrando os pontos de rupturas paradigmáticas do Custodial para o Pós-Custodial realizouse uma reflexão acerca das consequências destas rupturas paradigmáticas para Arquivologia.

Neste sentido, buscou-se verificar em qual momento houve a necessidade de se rever conceitos e normas, frente a um novo quadro que, com o avanço tecnológico, informacional e de comunicação, se fez presente no mundo atual, denotando-se, assim, a relevância do tema como forma de conhecimento do processo e diferentes possibilidades percorridas pela Arquivologia, contemplando seu desenvolvimento, tempo e lugar.

O trabalho inicia-se, assim, com a explanação acerca da Arquivologia 
Custodial, com uma breve contextualização histórica precedida da necessidade de instituição da avaliação de documentos frente ao grande volume da produção de arquivos públicos e privados da época.

Na sequência, abordou-se a fase da arquivologia Pós-Custodial, com novos conceitos em oposição a fase supracitada, a qual apresenta uma abordagem moderna, virtual e ativa de armazenamento arquivístico.

Por fim, apresenta-se a análise, bem como as evidências dos impactos ocasionados pelas rupturas paradigmáticas na arquivologia custodial para póscustodial. Para a compreensão dessa análise, foi realizado um estudo qualitativo, exploratório, bibliográfico e documental por meio de literatura científica nacional e internacional.

\section{ARQUIVOLOGIA CUSTODIAL}

A Arquivologia clássica, a qual se estabilizou no século XIX, tem como objeto de estudo os documentos de arquivos, a qual surgiu da necessidade do domínio das Humanidades de fazer parte de uma ciência, por meio do positivismo cujo padrão preponderante, originário das ciências ditas exatas e naturais, dirigido para as leis, regras, a perfeição da matemática e pelo conjunto de procedimentos técnicos, estendeu-se para as ciências sociais e humanas.

Diante dessa premissa, Zammataro (2013) leciona que o valor da custódia dos documentos tem relação histórica com o contexto da Revolução Francesa em 1789, em que os arquivos passam a pertencer ao Estado Liberal que, para custodiá-los, cria edificações específicas para tratamento, guarda e disponibilização afim de que houvesse regras de guarda, conservação, descrição, os quais espalhavam manuais e tratados nas instituições custodiadoras.

O reconhecimento desse movimento se deu com a divulgação do memorável Manual dos Arquivistas Holandeses de Muller, Feith e Fruinde (1898), que coloca a Arquivologia' em uma época em que a linha seguida é a

${ }^{1}$ Entre os termos Arquivologia e Arquivística, optou-se por Arquivologia. Porém, nas falas dos autores referenciados, será mantido o termo utilizado. 
técnica, além de outros manuais, conforme Schmidt (2012), de suma importância para compreender o desenvolvimento da noção de arquivo na Arquivologia, como, por exemplo, o manual italiano de Eugênio Casanova Archivistica (1928), Archivkunde de Adolf Brenneke e Wolfgang Lessch (1953) e A Manual of Archive Administration de Sir Hillary Jenkinson, publicado em (1922) e a revista em (1937).

Com o crescimento cada vez maior da produção documental, principalmente nas instituições públicas e privadas, houve a necessidade de uma avaliação de documentos, como requisito fundamental para preservação ou eliminação dos documentos. Desponta, então, na metade do século XX, uma outra visão, oriunda dos Estados Unidos da América (EUA) e do Canadá: a gestão de documentos. Assim, surge um debate de questões a respeito dos arquivos permanentes, correntes e intermediários sob a guarda da administração pública e privada. De acordo com Cruz (2016) desenvolveu-se nesse momento, duas nomenclaturas: o arquivo para a Arquivologia norte-americana e os arquivos para a Arquivologia europeia.

Na visão de Schmidt (2012, p. 144) " [...] é um tempo no qual a gestão administrativa, aliadas às inovações tecnológicas, ganha fôlego e demanda novas atitudes por parte da Arquivologia e seus profissionais [...]."

Partindo deste pressuposto custodial, a próxima seção, continua a abordagem acercada Arquivologia, com o enfoque no pós-custodial.

\section{ARQUIVOLOGIA PÓS-CUSTODIAL}

Ao se pautar à nova condição que foi alçada a Arquivologia, com o intuito de conhecê-la bem como para uma melhor compreensão da relação entre o custodial e o pós-custodial na literatura arquivística, Silva (2015) explica que pósmoderno é quando algo deixa de ser passivo, sai do ponto fundamental do técnico-científico e " [...] começaríamos a redefinir um novo lugar para a ciência, pois no mundo pós-moderno, a representatividade unificadora na maneira de pensar o mundo social deixaria de existir" (SILVA, 2015, p. 13).

Assim, pode-se observar que algumas características aproximam os paradigmas que rodeiam a Arquivologia, seja no custodial como no pós- 
custodial. Nesse sentido, Soares, Pinto e Silva (2015, p.26-27) descrevem no

Quadro 1, as distintas abordagens que norteiam a Arquivologia.

\section{Quadro 1 - Paradigma Custodial x Paradigma Pós-Custodial}

\begin{tabular}{|l|}
\hline PARADIGMA CUSTODIAL \\
\hline Sobrevalorização da custódia ou guarda, \\
conservação e restauro do suporte como \\
função basilar da atividade profissional de \\
arquivistas e bibliotecários; \\
Identificação do serviço/missão custodial \\
e pública do Arquivo e da Biblioteca com a \\
preservação da cultura "erudita" ou \\
"superior" (as artes, as letras, a ciência) de \\
um Povo em antinomia mais ou menos \\
explícita com a cultura popular, "de massas" \\
e os "produtos de entretenimento";
\end{tabular}

Enfatização da memória como fonte legitimadora do Estado-Nação e da cultura como reforço identitário do mesmo Estado, sob égide de ideologias de pendor nacionalista;

Importância crescente do acesso ao "conteúdo" através de instrumentos de pesquisa (guias, inventários, catálogos) dos documentos percepcionados como objetos patrimonializados, permanecendo, porém, mais forte o valor patrimonial do documento que o imperativo informacional;

Prevalência da divisão e assunção profissional decorrente da criação e desenvolvimento dos serviços/instituições Arquivo e Biblioteca, indutora de um arreigado e instintivo espírito corporativo que fomenta a confusão entre profissão e ciência (persiste a ideia equívoca de que a profissão de arquivista ou de bibliotecário gera, naturalmente, disciplinas científicas autônomas como a Arquivística e a Bibliotecologia).

\section{PARADIGMA PÓS-CUSTODIAL}

Valorização da informação enquanto fenómeno humano e social, sendo a materialização num suporte um epifenômeno;

Constatação do incessante e natural dinamismo informacional oposto ao "imobilismo" documental, traduzindo-se aquele no trinômio criação-seleção natural/acesso-uso e 0 segundo na antinomia efémero/permanente;

Propriedade máxima concedida ao acesso à informação por todos mediante condições específicas e totalmente definidas e transparentes, pois só o acesso público justifica e legitima a custódia e a preservação;

Imperativo de indagar, compreender e explicar (conhecer) a informação social, através de modelos teórico-científicos cada vez mais exigentes e eficazes, em vez do universo rudimentar e fechado da prática empírica composta por um conjunto uniforme e acrítico de modos/regras de fazer, de procedimentos só aparentemente "assépticos" ou neutrais de criação, classificação, ordenação e recuperação;

Alteração do atual quadro teórico-funcional da atividade disciplinar e profissional por uma postura diferente sintonizada com o universo dinâmico das Ciências Sociais e empenhada na compreensão do social e do cultural; e

Substituição da lógica instrumental, patente nas expressões "gestão de documentos" e "gestão da informação", pela lógica científicocompreensiva da informação na gestão, isto é, a informação social está implicada no processo de gestão de qualquer entidade organizacional

Fonte: Silva, (2006, p. 19-22), apud, Soares; Pinto; Silva,(2015, p. 26-27).

Conforme Tognoli (2010) é diante desta conjuntura de rompimento de paradigma, de propor novas fórmulas e de uma nova interpretação de princípios e métodos, relacionado à análise de organização do conhecimento arquivístico, que três diferentes abordagens surgem no Canadá quais sejam: a Arquivística Integrada, a Arquivística Pós-Moderna e a Diplomática Arquivística. Ainda, de 
acordo com (TOGNOLI, 2010), se faz de suma importância enfatizar que, este modo de compreensão do saber arquivístico, além de ter surgido a partir da manifestação do novo paradigma no final de 1980, reúne os principais componentes das abordagens canadenses.

No começo da década de 1990, Terry Cook, um dos precursores dessa teoria, retrata e repensa a obediência às regras da Arquivística, suas concepções e métodos e o próprio exercício do arquivista. Essa nova forma de expressar coloca, diante da arquivologia, novos conceitos em oposição aos velhos. Nesse sentido, pode-se observar como exemplo desses, o objeto na arquivologia pos custodial, o qual passa de físico e passivo para uma abordagem moderna, virtual e ativa, cujos lugares virtuais, de armazenamento virtual de estrutura e lugar para funções substituem os físicos. Assim, de acordo com Cook (2012, p.124) podese observar que "Uma profissão enraizada no Positivismo do século XIX, muito mais do que em estudos anteriores ligados à Diplomática, resultou em estratégias e metodologias que já não são viáveis num mundo pós-moderno e computadorizado", ou seja, uma mudança de paradigmas.

No entanto, essa mudança de paradigma não acontece de forma rápida e automática, uma vez que, conforme aponta Silva Neto (2011) há o envolvimento de métodos complicados que analisam crises e revoluções.

Dessa forma, pode-se observar que esse processo de transformação ocorre quando um dos dois paradigmas ganha a aprovação da maior parte dos integrantes das comunidades científicas, e, como mencionado por Silva Neto (2011), seja tal processo denominado de revolução científica, esse pode ser lento e demandar muito tempo.

Verifica-se, assim, que o novo paradigma acaba se tornando conhecido e objeto de um novo exercer, uma prática normal ainda que, em alguma situação, esse pode conter traços do paradigma tradicional.

Ainda, nesse sentido, nota-se que a alteração de paradigma aproxima a Arquivologia com a Ciência da Informação, conforme ensinam Soares, Pinto e Silva (2015) uma vez que pressupõe-se que o objeto científico não é mais o documento e sim a informação.

Ademais, Ribeiro (2005) aponta que esse novo paradigma exige uma 
formação adequada do arquivista e que esse esteja pronto para as respostas aos duelos impostos pela Tecnologia da Informação e Comunicação e pela sociedade da informação. Nesse sentido, Fernal e Franklin (2015, p.5) pontuam que "os objetos digitais são casos paradigmáticos de um novo tipo de documentação". A próxima seção irá analisar a repercussão desta trajetória na Arquivologia.

\section{EVIDÊNCIAS DOS IMPACTOS DA RUPTURAS PARADIGMÁTICAS NA ARQUIVOLOGIA CUSTODIAL PARA PÓS-CUSTODIAL}

A Revolução Francesa, a qual gerou grandes criações e mudanças, ao tange à Arquivologia, fora responsável pelo surgimento do princípio da proveniência ou respeito aos fundos, conceituando-se os princípios arquivísticos, os quais a norteiam e que são essenciais para o entendimento do proceder arquivístico e que a distingue de outras ciências documentárias, tendo por deferência a maneira como o Manual dos Arquivistas Holandeses conceituou arquivo, documento de arquivo, organização e descrição de documentos. Assim, "[...] foi criado o primeiro paradigma da Arquivologia, pois abordou a ideia de organicidade, dos dois princípios e o conceito de fundo [...]" (SCHMIDT, 2012, p. 115-116).

Observa-se, assim, que o Positivismo traz um padrão dominante, que era utilizado nas ciências exatas e que passou a ser aplicado às ciências sociais dirigido para as leis, regras, a perfeição da matemática e pelo conjunto de procedimentos técnicos. A publicação do Manual dos Arquivistas Holandeses, em 1898, coloca a Arquivística no domínio das disciplinas.

Tanto Arquivos, Bibliotecas e Museus aperfeiçoam seus métodos utilizados no tratamento dos seus acervos, separando as áreas e suas especificidades. O arquivo, enfim, se desliga lentamente do conceito de ser considerado somente um auxiliar da história. A publicação do Manual of Archival Administration, por Sir Hilary Jenkinson em 1922, corroborou com esta ideia.

Já no século XX, em meados dos anos 1950, ao término da Segunda Grande Guerra Mundial, surge o Conselho Internacional de Arquivos (CIA). Em 1960 desponta uma inquietação real na parte técnica da arquivística. Os anos 
de 1980 e 1990 se firmaram com mudanças profundas no campo audiovisual e na relevância da informática na criação de novos documentos. Assim, pode-se verificar a abrangência que o impacto do avanço tecnológico causou em nível global, alcançando as várias áreas do conhecimento, das ciências, inclusive a Arquivologia.

Por conseguinte, a concepção de verdade apresentada pelo Positivismo, propiciou algumas incertezas. Supõe-se manifestar um processo recente no conceito da conjuntura da Arquivologia, isto é, uma ruptura de paradigmas. Estas rupturas se baseariam nas modificações tecnológicas ocorridas ao longo dos anos. Essa atual maneira de conceber e guardar informação requer uma nova visão em relação às aplicações arquivísticas, admitindo a possibilidade destes métodos e os princípios da Arquivologia não corresponderem de forma eficaz no contexto do pós-moderno.

Para Cook (2012) os documentos arquivísticos não são mais vistos como objetos físicos e estáticos, mas em uma percepção virtual dinâmica, não somente como produto passivo do percurso e gestão humana e sim tornando dinâmica a construção da memória e da organização. Sem imobilidade, mas, integração na funcionalidade e no fluxo do trabalho. Em relação aos princípios arquivísticos, Cook (2012) segue afirmando que serão resguardados, mas, poderá haver discrepância na mudança de paradigmas se os arquivistas continuarem com suas pesquisas baseadas no princípio da proveniência e ordem dos documentos.

Segundo Schmidt (2014), Terry Cook, um dos precursores do tema acima mencionado, impõe como dever uma análise atenta do saber e do fazer dos que participam de uma comunidade científica, o qual fundamenta seu pensamento em admitir como verdadeira uma mudança de paradigma que se movimenta no novo século e sem chance de retroceder. Tal análise é feita por meio das premissas teóricas e práticas relacionadas com o conhecimento científico, assegurando que, se aceita ou não, se vive no tempo da ciência pós-moderna e esse pensamento já se encontra mergulhado em áreas do conhecimento como a história e a antropologia.

Ainda, de acordo com Schmidt (2014), o discurso desse autor infere o pós- 
moderno como componente inato do mundo contemporâneo em cujas normas a Arquivologia deve estar inclusa, senão se encontrará fora do que se assume como verdadeiro na dianteira intelectual, já que, as transformações, inovações constantes do mundo, atingem o âmbito das etapas documentais e o próprio documento, passando a possuir uma nova forma, uma vez que "Nesse contexto de reformulações e reinterpretações conceituais e disciplinares, o nome de Terry Cook aponta no horizonte arquivístico canadense como uma tentativa de fortalecer a disciplina e integrá-la às novas demandas de produção documental". (TOGNOLI, 2010, p.69)

Dessa forma, pode-se compreende-se que o pós-moderno traz consigo desacordos em relação ao desempenho de sua função e de seu emprego na interferência arquivística, uma vez que para os seguidores desta linha, nesta situação, o cientista e a ciência não se atam às leis comuns aplicadas.

Nesse contexto, esse processo de entendimento, do ponto de vista de Schmidt (2014), necessita de um estudo mais demorado. A concepção da verdade universal, de um conhecimento completo e aprofundado, são efeitos em sua totalidade de relevantes momentos históricos pelos quais as sociedades atravessaram, e que thes incluíram inúmeros progressos, ou seja, essas metamorfoses sofridas pelo mundo são empreendedores componentes de distinção do mundo contemporâneo.

Dessa forma, pode-se constatar que o raciocínio relativo à ciência também é o andamento contínuo e o que foi criado, levantado não pode ser liberado como devaneios. Diante disso, observa-se que a Arquivologia teve seu começo, antes deste mundo contemporâneo e faz parte deste sistema de crescimento e que ao se basear neste esquema, possibilita-se a construção de um novo paradigma.

Para Kuhn (1998) a competência científica é demarcada quando se é escolhido um paradigma: uma base mental constituída por teorias, experiências, métodos e instrumentos, servindo para o raciocínio ordenar deliberadamente a verdade e os seus fenômenos. Essa construção, que carrega em si fatores também psicológicos e filosóficos, é aceita e distribuída pela reunião dos que fazem parte de um agrupamento científico, surgindo uma unidade social apoiada 
em uma visão de mundo em concordância.

Ainda, de acordo com Kuhn (1998), esse novo paradigma passaria a explorar acontecimentos tidos como não importantes, além de atentar ao fato de que, após uma rebelião científica, despontam novos traços exclusivos de pesquisa. Esse encontro de linguagem do que se chama de incomensurabilidade, é a condição precisa para o desenvolvimento científico na acepção de expandir o conhecimento e não uma ameaça.

Nesse sentido, Tossato (2012) relata que a noção de expansão do conhecimento Kuhniano converte-se no ponto mais discutível de sua doutrina, a qual permite entender a falta de capacidade de determinar que fundamento se aplica a uma especialidade científica, uma vez que essa, em seus variados aspectos, contradiz a disponibilidade de opção entre teorias.

Destarte, ensinamentos sem semelhança impendem a mundos diferentes ou são proferidos em palavras inexprimíveis de uma teoria para outra teoria distinguível, ou as duas coisas, que, conforme Tossato (2012), não podem ser comensuradas por três motivos: o primeiro diz que paradigmas não concordam quanto aos problemas a serem resolvidos, em vista de que seus modelos e interpretação de ciência são desiguais; o segundo que paradigmas mantém concepções do antigo com outro sentido e o terceiro que o pesquisador se dedica às suas atividades em universos distintos, veem o assunto, mas de maneiras diferentes.

Esse tema simboliza o procedimento pelo qual um cientista abandona o paradigma que trabalhava seguindo um novo paradigma. No início, existe uma fase de transferência separando os seguidores do novo paradigma e os que permanecerão trabalhando com o paradigma antigo.

A seguir, o Quadro 2 demonstra uma lista de marcos acerca das rupturas paradigmáticas na Arquivologia, com informações pertinentes obtidas com base na correlação existente entre o custodial e o pós-custodial. 
Quadro 2 - Marcos das Rupturas Paradigmáticas da Arquivologia

\begin{tabular}{|c|c|c|c|}
\hline \multicolumn{4}{|c|}{ ARQUIVOLOGIA CUSTODIAL } \\
\hline $\begin{array}{c}1 \% \text { marco } \\
(1789)\end{array}$ & $\begin{array}{c}2^{\circ} \text { marco } \\
(1821)\end{array}$ & $\begin{array}{c}3^{\circ} \text { marco } \\
(1841)\end{array}$ & $\begin{array}{c}4^{\circ} \text { marco } \\
(1898)\end{array}$ \\
\hline $\begin{array}{l}\text { Revolução Francesa; } \\
\text { Institucionalização } \\
\text { do primeiro arquivo } \\
\text { público Frances } \\
\text { Com a Revolução } \\
\text { Francesa, o século } \\
\text { XVIII assiste a uma } \\
\text { grande transformação } \\
\text { nas histórias da } \\
\text { civilização e dos } \\
\text { arquivos. Até o final do } \\
\text { século XVII, os } \\
\text { arquivos eram } \\
\text { completamente } \\
\text { descentralizados e } \\
\text { serviam basicamente } \\
\text { à administração. Em } \\
1789, \text { é criado o } \\
\text { Arquivo Nacional da } \\
\text { França, antes Arquivo } \\
\text { da Assembleia, e } \\
\text { posteriormente, em } \\
1794, \text { no dia } \\
24 \text { de junho, } \\
\text { transformado nos } \\
\text { Archives Nationales. }\end{array}$ & $\begin{array}{c}\text { École national dês } \\
\text { Chartes; } \\
\text { Valor histórico dos } \\
\text { documentos; } \\
\text { Visionada por } \\
\text { Napoleão, a École } \\
\text { Nationale des Chartes } \\
\text { foi criada em } 1821 \text { por } \\
\text { uma ordem de Luis } \\
\text { XVIII. A razão de sua } \\
\text { criação foi a } \\
\text { necessidade de } \\
\text { formação de jovens } \\
\text { capazes de organizar } \\
\text { os depósitos de } \\
\text { documentos } \\
\text { confiscados na } \\
\text { Revolução, e renovar } \\
\text { a história nacional. } \\
\text { Assim, em 1829 é } \\
\text { criada a formação de } \\
\text { arquivista paleógrafo. }\end{array}$ & $\begin{array}{c}\text { Princípio de respeito } \\
\text { aos fundos; } \\
\text { Princípio da } \\
\text { proveniência; } \\
\text { Rapidamente adotado } \\
\text { por outros países } \\
\text { europeus, que } \\
\text { incorporaram a sua } \\
\text { prática e teorias } \\
\text { arquivísticas a } \\
\text { classificação por } \\
\text { fundos. É o caso da } \\
\text { Alemanha } \\
\text { (Provenienzprinzip), } \\
\text { da Inglaterra (archive } \\
\text { group), da Itália } \\
\text { (fondo) e da Espanha. } \\
\text { Nos Estados Unidos, o } \\
\text { princípio foi adotado } \\
\text { somente a partir do } \\
\text { século XX, sob o } \\
\text { termo record group. }\end{array}$ & $\begin{array}{c}\text { Manual dos } \\
\text { Arquivistas } \\
\text { Holandeses; } \\
\text { Codificou e padronizou } \\
\text { a metodologia } \\
\text { arquivística } \\
\text { antes que a teoria } \\
\text { pudesse se } \\
\text { desenvolver. } 0 \\
\text { Manual contribuiu, } \\
\text { portanto, para a } \\
\text { inserção da } \\
\text { Arquivística no campo } \\
\text { das disciplinas, dando } \\
\text { início às reflexões que } \\
\text { se seguiram no } \\
\text { começo do século XX. }\end{array}$ \\
\hline \multicolumn{2}{|c|}{ ARQUIVOLOGIA CUSTODIAL } & \multicolumn{2}{|c|}{ ARQUIVOLOGIA PÓS-CUSTODIAL } \\
\hline $\begin{array}{c}5^{\circ} \text { marco } \\
(1950)\end{array}$ & $\begin{array}{c}6^{\circ} \text { marco } \\
(1980)\end{array}$ & $\begin{array}{c}7^{\circ} \text { - Marco } \\
(1987)\end{array}$ & $\begin{array}{c}8^{\circ} \text { marco } \\
(1990)\end{array}$ \\
\hline Records Management & Arquivologia Integrada & Arquivologia Pós- & Documento Eletrônico \\
\hline $\begin{array}{c}\text { Gestão documental; } \\
\text { Cabia, portanto, aos } \\
\text { record managers } \\
\text { gerenciar a } \\
\text { documentação } \\
\text { corrente e } \\
\text { intermediária } \\
\text { produzida pelas } \\
\text { instituições, enquanto } \\
\text { que aos archivists } \\
\text { estavam ligados aos } \\
\text { documentos que } \\
\text { poderiam ser } \\
\text { considerados de } \\
\text { cunho histórico } \\
\text { permanente. }\end{array}$ & $\begin{array}{l}\text { Uma nova abordagem } \\
\text { surge no Canadá } \\
\text { francês, com a } \\
\text { intenção de reintegrar } \\
\text { a disciplina, } \\
\text { trabalhando } \\
\text { novamente com todo o } \\
\text { ciclo documental, dos } \\
\text { documentos correntes } \\
\text { até os permanentes. É } \\
\text { a chamada } \\
\text { Arquivística Integrada, } \\
\text { cujos estudos estão } \\
\text { baseados nas } \\
\text { realidades europeia } \\
\text { dos documentos } \\
\text { históricos e norte } \\
\text { americana da gestão } \\
\text { documental. }\end{array}$ & $\begin{array}{l}\text { Proclamou e previu a } \\
\text { mudança de } \\
\text { paradigma } \\
\text { Hugh Taylor. } \\
\text { O objeto do novo } \\
\text { paradigma da ciência } \\
\text { arquivística: que é a } \\
\text { informação gerada } \\
\text { pelos processos } \\
\text { administrativos e } \\
\text { estruturada por esses } \\
\text { processos com } \\
\text { objetivo de permitir } \\
\text { uma recuperação } \\
\text { contextual, com o } \\
\text { contexto desses } \\
\text { processos como ponto } \\
\text { de partida. }\end{array}$ & $\begin{array}{c}\text { Agora, o princípio } \\
\text { deixa de ser estático e } \\
\text { passa a ser um } \\
\text { princípio dinâmico e } \\
\text { funcional, que } \\
\text { condiz muito mais com } \\
\text { a realidade } \\
\text { organizacional em que } \\
\text { a estabilidade } \\
\text { estrutural desapareceu } \\
\text { e podendo ser } \\
\text { utilizado com muito } \\
\text { mais valor na era dos } \\
\text { documentos } \\
\text { eletrônicos, com a } \\
\text { dinamicidade } \\
\text { caracterizando os } \\
\text { processos de criação } \\
\text { dos registros }\end{array}$ \\
\hline
\end{tabular}

Fonte: Elaborada pelos autores com base em Rocco (2013); Rondinelli (2004); Tognoli (2010). 
O primeiro marco da Arquivologia foi a Revolução Francesa, em 1789, que propiciou o surgimento da criação do arquivo público Francês, o qual reconhece a relevância do documento, bem como a responsabilidade do Estado Francês na custodia dos documentos. Diante disso, o século XVIII presencia uma grande transformação na história da civilização e dos arquivos.

O segundo marco foi a École National dês Chartes, criada na França em 22 de fevereiro de 1821, na cidade de Paris, a qual serviu para robustecer a relação entre a Arquivologia e a História (TOGNOLI, 2010) a partir de uma determinação de Luís XVII, já que o conhecimento e a cultura estavam nas mãos do Estado e precisavam de especialistas que pudessem ler os arquivos e os escritos confiscados durante a Revolução, renovando-se, assim, a história francesa. Para tanto, estudaram paleografia e filologia.

O terceiro marco, o princípio de respeito aos fundos, consistia em reunir os documentos em fundos, ou seja, deixar em grupos os documentos vindos da única instituição, família, pessoa, sem misturar com outros (TOGNOLI, 2010). O princípio de respeito aos fundos tem a dimensão semelhante do princípio da proveniência, respeitando a ordem dos documentos e restabelecendo caso seja perdida, esta ordem original.

O quarto marco, o célebre o Manual dos Arquivistas Holandeses, no ano de 1898, publicação feita pelo trio de arquivistas holandeses S. Muller, J.H Feith e R. Fruin, enxergaram os arquivos como domínio de conhecimento preestabelecidas e livres de outras disciplinas, marcou o começo de uma nova era para os arquivo. Sua divulgação foi caracterizada como base da teoria arquivística, um grande sinal teórico, já que sistematizou e documentou os princípios da proveniência e da ordem original, fundamentos da descrição e do arranjo em arquivos. Como consequência desta publicação, o arquivo começou a ser visto como o panorama de conjunto orgânico, sendo além de demarcação de entrada, um fortalecimento no progresso da Arquivologia no campo científico.

Por conseguinte, em 1922, na Inglaterra, foi publicado, por Sir Hilary Jenskinson, o A Manual of Archival Administration, outra relevante contribuição para estabilizar e fortificar a disciplina. Esse modo de contemplar os documentos como resultado oriundo de operações e feitos administrativos, favorece os 
documentos no sentido de imparcialidade e neutralidade. Para o autor supracitado, os arquivos deveriam ser conservados por quem os criou e para uso próprio, sem levar em conta a parte histórica e de pesquisa, uma vez que o arquivista era um guardião dos documentos.

O quinto marco, Records Management, a gestão documental. No começo do século XX, após a Segunda Guerra Mundial, devido ao aumento da massa documental $e$ as distintas ações conferidas ao documento de arquivo, proveniente dos novos cargos e funções acumulados nas administrações, surge nos EUA uma nova abordagem arquivística, idealizada pelo arquivista norteamericano Schellenberg. Com o intuito de simplificar e organizar a produção de documentos produzidos pelos arquivos públicos e privados, surgem novas concepções acerca dos valores dos seus papéis, títulos. Este período foi até 1980, também conhecido como Arquivologia Moderna.

O autor, supracitado no parágrafo anterior, desenvolveu a noção de avaliação para que fosse escolhido e preservado somente o documento que servisse de fonte de pesquisa, com dois valores: primário com fins administrativos, fiscais, legais e secundários para fins probatórios e informativos e históricos.

Também neste período pós-guerra, surge o conceito do ciclo vital dos documentos ou teoria das três idades, disseminada por Schellenberg em 1956. A primeira idade é denominada de arquivo corrente, tipologia, função e vigência dos documentos. A segunda idade de arquivo intermediário, na qual os documentos já passaram pelo seu prazo de validade, podendo ainda ser utilizados pelo seu produtor e a terceira, o chamado arquivo permanente, a qual consiste-se em documentos preservados e conservados como patrimônio documental. Assim surge uma norma para o controle do documento, tomandose por base sua criação até a sua eliminação ou guarda definitiva.

O sexto marco, a Arquivologia Integrada. No percurso destas mudanças, surge, em 1980, a Arquivologia Integrada, com a proposta de trabalhar todo 0 ciclo documental, baseada nos estudos da parte europeia como documentos históricos e na norte-americana com a gestão documental, uma vez que "Nesse sentido, a Arquivística Integrada busca uma reintegração da disciplina, focando 
seus estudos na gestão da informação orgânica e em sua importância para o fortalecimento da disciplina nos séculos XX e XXI." (TOGNOLI 2010, p. 7). As expressões informação orgânica e informação não-orgânica são resultados da abordagem quebequense das quais compreendem-se por informação orgânica a que foi produzida ou recebida durante uma atividade e não orgânica são as que estão em documentos bibliográficos.

Assim, ao se determinar o objeto da Arquivologia como a informação orgânica registrada, o ponto de vista quebequense introduz a disciplina na chamada "[...] era da informação, integrando manager e archivist em uma só profissão, de maneira a garantir a sustentação da Arquivística em um novo contexto de produção de informações" (TOGNOLI, 2010, p. 8).

O sétimo marco, a Arquivologia pós-custodial, a informação é o que se leva em consideração como manifestação humana e social, não tendo a interferência ou influência do suporte. $O$ que se oferece no pós-custodial é o ininterrupto e espontâneo movimento da informação sem oposição sistemática a progressos e inovações. Há uma mudança de postura no quadro teóricofuncional da atividade disciplinar e profissional, que entra em sintonia com as ciências sociais, buscando uma maior compreensão sobre o social e a cultura, no padrão de formação dos que virão a ser especialistas da informação. Por fim, expõe a alteração de gestão de documentos para a gestão da informação. Nesta última, o raciocínio científico-compreensivo é que a informação social está subtendida no processo de administração de qualquer entidade organizacional e de forma que os gestores destas informações compreendam as práticas informacionais e busquem traçar as soluções para as evoluções futuras.

O oitavo marco, o documento eletrônico. $O$ final do século $X X$ foi marcado pelas mudanças tecnológicas e sociais, um novo mundo digital. Nesse sentido, havia um questionamento acerca de como a Arquivologia está compreendendo essas mudanças, isto é, o que realmente significam e interferem na área a ponto de se anunciar, afirmar uma nova era.

Nesse novo cenário de reformulação e reinterpretação, e de mudança paradigmática, relativamente às perspectivas de organização do conhecimento arquivístico, uma nova corrente emergiu no Canadá Inglês: a Arquivística Funcional ou Pósmoderna, cujo objetivo é defender e repensar os princípios, 
conceitos e métodos basilares da disciplina, para que essa possa adaptar-se e sobreviver na contemporaneidade. (TOGNOLI, 2010, p. 57).

O novo paradigma considera e conceitua seu objeto de estudo: a informação, em seu ambiente digital. O que antes era compreendido como o conjunto de documentos gerados e recebidos por uma entidade ou pessoa no decorrer de uma atividade, "[...] passa a ser compreendido como o conjunto de informações orgânicas, registradas em meios virtuais dinâmicos". (TOGNOLI, 2010, p.56).

Nesse sentido, pode-se observar que "Os documentos de arquivo em âmbito digital não necessitam de ambiente físico, pois as informações registradas serão tratadas em suportes digitais (PIMENTEL,2016, p.17)". Com isso, o foco do seu objeto científico deixa de ser o documento de arquivo e passa a ser a informação orgânica, característica essa cada vez menos sem fronteiras, muros e papeis.

Ademais, conforme afirma COOK (2012) que gostando ou não, vive-se na conjuntura de uma época pós-moderna e que, dentro deste âmbito, a Arquivologia é vista como produtora de conhecimento científico e cabe ao arquivista o papel de produtor, passando de ser passivo para ser ativo na construção da memória coletiva.

Diante do percurso percorrido pela Arquivologia, descrito no quadro 2 percebe-se que a Arquivologia Custodial é voltada para o tecnicismo, para o historicismo e o estático. Para que haja o começo de uma Arquivística Pósmoderna é necessário reconhecer o novo paradigma enunciado por Taylor e aprofundados por Terry Cook, "[...] que também admite a obsolescência dos princípios e métodos arquivísticos gerados no século XIX, defendendo seu repensar para a sobrevivência e adaptação da disciplina nos dias atuais" (TOGNOLI; GUIMARÃES, 2011, p. 30).

Nesse contexto, o arquivista deve ter em mente que ao avaliar, selecionar os documentos que serão preservados, sejam para fins históricos e culturais, ele será responsável por moldar uma herança documental, uma vez que vai selecionar entre o que deve ser lembrado e o que deve ser esquecido pela sociedade. Conforme Tognoli "[...] nós, arquivistas, estamos literalmente co- 
produzindo os arquivos. Nós estamos fazendo história. Estamos exercendo o poder sobre a memória" (COOK, 2006, p. 103 apud TOGNOLI, 2010, p. 80).

Destarte, observou-se, assim, com a explanação dos marcos da arquivologia, por meio do quadro 2 , os impactos das rupturas paradigmáticas bem como a necessidade de reflexão realizada na presente pesquisa, não se olvidando acerca da preocupação de como seus princípios, funções e teorias.

\section{CONSIDERAÇÕES FINAIS}

Frente ao caminho traçado pela Arquivologia, em suas fases custodial e pós-custodial, evidenciando seus marcos paradigmáticos bem como a ruptura de paradigma, fora possível constatar dois pontos relevantes quais sejam: a evolução da Arquivologia baseada nas técnicas criadas ao longo do seu percurso que norteiam toda a sua história e o impacto, que a evolução do avanço tecnológico traz para a área, no momento atual.

Verificou-se que o paradigma custodial, comprovado pela literatura arquivística, durante todo o seu trajeto, fundamentado nas bases teóricas e práticas da Arquivologia e expressa nos manuais e princípios no final do século XIX, assumiu a posição tecnicista de organizar, preservar e custodiar os documentos de arquivo enquanto o pós-custodial propiciou novos questionamentos e implicações acerca do documento arquivístico digital para a correção de problemas presentes no final do século $\mathrm{XX}$, marcados pelas tecnologias que passaram a assinalar às mudanças observadas no contexto de produção da informação.

Notou-se, assim que essa nova interpretação busca aproximar a Arquivologia, inserida no campo do saber, com a Ciência da Informação, a qual parte do pressuposto que ambas as áreas partilham de único objeto de investigação científica, qual seja: a informação.

Assim, diante do estudo destas abordagens, percebeu-se que a ruptura de paradigmas entre a Arquivologia custodial e a Arquivologia pós-custodial, ainda não foi discutida de forma abrangente e conclusiva. Ademais, observouse, a partir da literatura selecionada para a presente pesquisa, que as contribuições acerca do tema, mesclam tanto a importância da parte tecnicista e 
de guarda, quanto a da fluidez do mundo pós-moderno, o que não significa que haja uma liberdade, no pós-moderno, para a construção deste novo paradigma e que ignora o que já foi construído, conforme a determinação do que são contemporâneos.

Dessa forma, o que se tem é uma repetição de padrões que existiram quando da passagem do pré-moderno para o moderno. Essa reconstrução toma a forma em situações particulares, cuja abordagem paradigmática pós-custodial da Arquivística indica uma mudança do objeto de estudo, visto o novo cenário que estabelece a tecnologia. Seus desafios são em esfera global e levam esta área da ciência a repensar velhos conceitos, reformularem preceitos e se fortalecer no campo do conhecimento científico.

\section{REFERÊNCIAS}

CERVO, Amado Luiz; BERVIAN, Pedro Alcino; SILVA, Roberto da. Metodologia científica. 6. ed. São Paulo: Pearson Prentice Hall, 2007. COOK, Terry. Arquivologia e Pós-modernismo:novas formulações para velhos conceitos. Informação Arquivística. Rio de Janeiro, RJ, v. 1, n. 1, p. 123-148, jul./dez. 2012. Disponível em:

http://www.aaerj.org.br/ojs/index.php/informacaoarquivistica/article/view/9/20Ac esso em: 05 abr. 2018.

CRUZ, Emília Barroso. Acesso e gestão da informação governamental do tipo arquivístico: aspectos técnicos e a visão de gestores e servidores de duas instituições governamentais. 2016. 226 f. Tese (Doutorado em Ciência dalnformação) - Instituto Brasileiro de Informação em Ciência e Tecnologia, Universidade Federal do Rio de Janeiro, Rio de Janeiro, 2016.Disponível em: http://ridi.ibict.br/bitstream/123456789/882/1/Em\%C3\%ADlia\%20Barroso\%20Cr uz\%20-\%20Tese\%2027072016.pdf. Acesso em: 25 nov. 2018.

FERNAL, Alexandre; FRANKLIN, Benjamin Luiz. Materialidade da informação nos ambientes informacionais digitais e os impactos na arquivologia.

In:ENCONTRO NACIONAL DE PESQUISA EM CIÊNCIA DA INFORMAÇÃO, 16., 2015, João Pessoa. Anais [...] João Pessoa: ANCIB: UFPB, 2015, p. 1 19.Disponível; em:

http://www.ufpb.br/evento/lt/ocs/index.php/enancib2015/enancib2015/paper/vie w/2987/1183. Acesso em: 07 abr. 2018.

GIL, Antonio Carlos. Métodos e técnicas de pesquisa social. 7. Rio de Janeiro Atlas 2019.

KUHN, Thomas. A estrutura das revoluções científicas. Tradução: Beatriz Vianna Boeira e Nelson Boeira.5 eds. São Paulo: Perspectiva S.A, 1998, 259 p. 
MARTINS, Gilberto de Andrade; LINTZ, Alexandre. Guia para elaboração de monografias e trabalho de conclusão de curso. São Paulo: Atlas, 2000. PIMENTEL, Jorlânio de Miranda. Da concepção da visão custodial para a pós-custodial no âmbito da gestão documental: uma discussão em aberto na literatura e na prática. 2016. 25 f. Trabalho de conclusão de curso (Graduação em Arquivologia) - Universidade Federal da Paraíba, João Pessoa, 2016.Disponível em: www.aaerj.org.br/ojs/index.php/informacaoarquivistica/article/download/66/31. Acesso em: 01 dez. 2018.

RIBEIRO, Fernanda.Os Arquivos na era pós-custodial: reflexões sobre a mudança que urge operar. Boletim Cultural da Câmara Municipal de Vila Nova de Famalicão 2005. Disponível em:

http://ler.letras.up.pt/uploads/ficheiros/artigo10091.pdf. Acesso em: 02 jul. 2018.

ROCCO, Brenda Couto de Brito. Um estudo sobre a gestão de documentos arquivísticos digitais na administração pública federal brasileira. 2013. 130f. Dissertação (Mestrado em Ciência da Informação) - Instituto Brasileiro de informação em Ciência e Tecnologia, Universidade Federal do Rio de Janeiro, Rio de Janeiro, 2013. Disponível em: http://ridi.ibict.br/bitstream/123456789/711/1/rocco2013.pdf. Acesso em: 04 dez. 2018.

RONDINELLI, Rosely Curi. Gestão arquivística de documentos eletrônicos. Rio de Janeiro: FGV, 2004. 158 p.

SCHMIDT, Clarissa Moreira dos Santos. Arquivologia e a construção do seu objeto científico: concepções, trajetórias, contextualizações. 2012. 320 f. Tese (Doutorado em Ciência da Informação) - Universidade de São Paulo, São Paulo,2012. Disponível em: https://teses.usp.br/teses/disponiveis/27/27151/tde02072013-170328/publico/ClarissaMSSchmidt_revisada.pdf. Acesso em: 31 jan. 2018.

SCHMIDT, Clarissa Moreira dos Santos. O clássico e o pós-moderno: algumas reflexões acerca da arquivologia a partir do pensamento de Hilary Jenkinson e Terry Cook. Informação Arquivística, Rio de Janeiro, v. 3, n. 1, p. 42-59, jan./jun. 2014. Disponível em:

www.aaerj.org.br/ojs/index.php/informacaoarquivistica/article/download/66/31. Acesso em: 07 abr. 2018.

SILVA NETO, Sertório de Amorim e. O que é um paradigma? Revista de Ciências Humanas, Florianópolis, v. 45, n, 2, p. 345-354, out. 2011. Disponível em: https://periodicos.ufsc.br/index.php/revistacfh/article/viewFile/21784582.2011v45n2p345/22356. Acesso em: 13 out.2018.

SILVA, Luiz Eduardo Ferreira da. Uma ruptura a-significante: o desconstruir-se a ideia de uma "nova ciência arquivística pós-moderna" sob uma ótica pósestruturalista. Informação Arquivística, Rio de Janeiro, v. 4, n. 1, p. 25-40, jan./jun. 2015. Disponível em: 
www.aaerj.org.br/ojs/index.php/informacaoarquivistica/article/download/82/52. Acesso em: 08 jun. 2018.

SOARES, Ana Paula Alves; PINTO, Adilson Luiz; SILVA, Armando Malheiro da. O paradigma pós-custodial na arquivística. PÁGINAS a\&b. Porto, v. 3, n. 4, p. 22-39, 2015. Disponível em:

http://ojs.letras.up.pt/index.php/paginasaeb/article/view/996/905. Acesso em: 07 abr. 2018.

TOGNOLI, Natália Bolfarini. A contribuição epistemológica canadense para a construção da arquivística contemporânea. 2010. 120 f. Dissertação (Mestrado em Ciência da Informação)-Universidade Estadual Paulista Júlio de Mesquita Filho, Marília, 2010. Disponível em:

https://www.marilia.unesp.br/Home/Pos-

Graduacao/Cienciadalnformacao/Dissertacoes/tognoli_nb_me_mar.pdf. Acesso em: 16 jan. 2018.

TOGNOLI, Natália Bolfarini;. GUIMARÃES, José Augusto Chaves. Arquivística pós-moderna, diplomática arquivística e arquivística integrada: novas abordagens de organização para a construção de uma disciplina contemporânea. In:ENCONTRO NACIONAL DE PESQUISA EM CIÊNCIA DA INFORMAÇÃO, 11., 2011, Rio de Janeiro. Anais [...]. Rio de Janeiro,ANCIB: IBICT,2010.Disponível em:http://enancib.ibict.br/index.php/enancib/xienancib/paper/viewFile/3415/254 1. Acesso em: 06 abr. 2018.

TOSSATO, Claudemir Roque. Incomensurabilidade, comparabilidade e objetividade.Scientiae Studia, São Paulo, v.10, n.3, 2012. Disponível em: http://www.scielo.br/scielo.php?script=sci_arttext\&pid=S1678-

31662012000300004 . Acesso em: 12 nov. 2018.

VIEIRA, Thiago de Oliveira. Alguns aportes para os limites de uma arquivologia contemporânea. ÁGORA: Revista do Curso de Arquivologia da UFSC, Florianópolis, v. 23, n. 46, p. 45-57, jun. 2013. Disponível em: https://agora.emnuvens.com.br/ra/article/view/437. Acesso em: 07 nov. 2018.

ZAMMATARO, Ana Flávia Dias. Concepção de arquivo no contexto pósmoderno: um diálogo com a arquivologia pós-custodial. In: SEMINÁRIO EM CIÊNCIA DA INFORMAÇÃO. 5., 2013, Londrina.Anais [...]Londrina:UEL, 2013, p. 352-369.Disponível em:http://www.uel.br/eventos/cinf/index.php/secin2013/secin2013/paper/viewFil e/115/85. Acesso em: 01 abr. 2018.

\section{BREAKDOWN OF PARADIGMS IN CUSTODIAL ARCHIVAL SCIENCE FOR POST-CUSTODIAL}

\section{ABSTRACT}


Objective: In this way, we sought to analyze and highlight the paradigmatic breaking points and their impacts on the custodial archives for the post custodial one. Therefore, the bases of custodial and post custodial archival science were analyzed, demonstrating differences and similarities between them. Methodology: This is a bibliographic, exploratory, qualitative and documentary research on national and international scientific literature published in books, articles, theses and dissertations. Results: By presenting the paradigm shifts that gave rise to conceptual and disciplinary reformulations and reinterpretations regarding the theme, based on their theoretical frameworks throughout history, what are their breaking points, their reflected consequences, as well as the new ones interpretations, it was verified, therefore, the possibility of constructing a new paradigm in face of the situations presented in the contemporary context, of proposing new formulas and of a modern interpretation of principles and methods, related to the analysis of the organization of archival knowledge. Conclusion: By demonstrating the disruptions and their impacts, therefore, considering the complexity and dissent still present on the subject, there is an urgent need for continuous reflection, studies and contributions on the matter in question, regarding the paradigmatic ruptures from custody archival science to post custody.

Descriptors: Archival Science. Archival Science Custody. Archival Science Post Custody. Paradigms.

\title{
RUPTURAS DE PARADIGMAS EN ARCHIVISTICA CUSTODIAL PARA POST-CUSTODIAL
}

\begin{abstract}
RESUMEN
Objetivo: De esta manera, se buscó resaltar y resaltar los puntos de ruptura paradigmáticos y sus impactos en los archivos custodiales para el post-custodia. Por tanto, se analizaron las bases de la archivística custodia y pos-custodia, demostrando diferencias y similitudes entre ellas. Metodología: Se trata de una investigación bibliográfica, exploratoria, cualitativa y documental sobre la literatura científica nacional e internacional publicada en libros, artículos, tesis y disertaciones. Resultados: Al presentar los cambios de paradigma que dieron lugar a reformulaciones y reinterpretaciones conceptuales y disciplinarias sobre el tema, a partir de sus marcos teóricos a lo largo de la historia, cuáles son sus puntos de ruptura, sus consecuencias reflejadas, así como las nuevas interpretaciones, se verificó de ahí la posibilidad de construir un nuevo paradigma ante las situaciones que se presentan en el contexto contemporáneo, de proponer nuevas fórmulas y de una interpretación moderna de principios y métodos, relacionados con el análisis de la organización del conocimiento archivístico. Conclusión: Al demostrar las disrupciones y sus impactos, por lo tanto, considerando la complejidad y el disenso aún presente sobre el tema, se hace urgente la reflexión, los estudios y los aportes continuos sobre el tema en cuestión, sobre las rupturas paradigmáticas de la archivística custodia a la post-custodia.
\end{abstract}

Descriptores: Archivistica. Archivistica Custodia. Archivistica post-custodia. Paradigmas.

Recebido em: 15.04 .2021

Aceito em: 30.04.2021 